\title{
A REVIEW ON PROTEIN TYROSINE PHOSPHATASES - AN IMPORTANT TARGET FOR VARIOUS DISEASES
}

\author{
VENKATARAGHAVAN R, BRINDHA DEVI P*, IVO ROMAULD S
}

Department of Bio-Engineering, School of Engineering, Vels Institute of Science, Technology and Advanced Studies, Chennai - 600117, Tamil Nadu, India. Email: pbrindhadevi@gmail.com

Received: 03 March 2018, Revised and Accepted: 04 April 2018

\section{ABSTRACT}

The enzyme protein tyrosine phosphatase (PTP) is responsible for the regulation of cellular functions including cell growth, replication, and signal transduction. Dysregulation of this enzyme leads to various diseases including Type II diabetes and cancers as well. The PTP enzyme functions as a promising drug target for these diseases, leading to new innovations in developing new drug targets in the field of clinical studies and pharmacology. The PTP is considered as the next generation drug targets. The protein tyrosine drug targets can be targeted to cure the diseases caused due to its dysregulations. However, due to its complex structure and highly conserved active sites are the major challenges which block this strategy. Moreover, two enzyme proteins PTP A and PTP B of PTP enzyme family are essential for the survival of Mycobacterium in host macrophages and cause infection resulting in chronic tuberculosis. The novel drug-like properties of L335-M34 and L01Z08 compounds are selective inhibitors of this enzyme responsible for the tuberculosis virulence in mammals. Some of the commercial inhibitors such as ertiprotafib, arylbenzonaphthofurans, and arylbenzonaphthothiophenes have also proven to inhibit the enzyme's virulence. This review summarizes the latest innovations to lead a map for developing new innovative drugs against the various classes of target enzymes of tyrosine phosphatase.

Keywords: Protein tyrosine phosphatase, Diabetes, Cancer, Tuberculosis.

(c) 2018 The Authors. Published by Innovare Academic Sciences Pvt Ltd. This is an open access article under the CC BY license (http://creativecommons. org/licenses/by/4. 0/) DOI: http://dx.doi.org/10.22159/ajpcr.2018.v11i7.25615

\section{INTRODUCTION}

Protein tyrosine phosphatases (PTPs) (PTPase; EC 3.1.3.48) are the enzymes that cleave and remove the phosphate groups from the phosphorylated tyrosine residues present in the proteins. This process is referred to as protein tyrosine (pTyr) phosphorylation. PTP along with protein tyrosine kinases (PTKs) modulates the proper cellular level of pTyr phosphorylation process. pTyr phosphorylation is one of the typical post-transitional modification processes of proteins by creating a unique idea for various processes such as cellular localization, regulation of the protein activity, and also affects protein stability, as a result of which the maintenance of appropriate levels of pTyr phosphorylation is beneficial for many cellular activities. PTPs catalyze by cleaving and removing the phosphate group that is adhered to the tyrosine residues with the help of a cysteinyl-phosphate enzyme intermediate. These enzymes play a key role in the cell signal transduction pathways, cell growth, and replication, the transformation processes and cytoskeletal activity which response to various stimuli. The PTPs also act as tumor repressors and in T-cell activation. PTP plays a major role in curing oncogenes and as well as pathogenesis caused due to bacterial infections. Improper function of the PTKs and phosphatases are related to the analysis of numerous human diseases, including cancer, diabetes, and immune dysfunction. The main attributes and functions of PTP will govern the process of phosphorylation of cell signal transduction pathways like mitogen-activated protein kinases. The major roles of this enzyme are cell growth, replication, differentiation, mitosis, the transformation of oncogenes, and receptor endocytosis (Dutta et al. 2015).

\section{The active site of the enzyme}

Determining the active site of the enzyme PTPs plays a major role in the inhibition of its virulence. Several studies are going onto inhibit the enzyme's activity by finding a suitable ligand that could bind to the cleft pocket efficiently. PTPB possesses similar central, canonical and also 4 stranded parallel $\beta$ sheets with the PTPs. In comparison with the complexity of structure PTPs such as PTP1B and PTPB, the PTPB is intensely diverged and structurally simplified. The PTPB is structurally homologous to PTP1B (Fig. 1). With the disparity to the diverged folds, the enzyme PTPB projects the similar active center region as that of other PTPs (Grundner et al., 2005). In the active site of this enzyme, the catalytic cysteine, Cys160 is present within the loop P concurrence sequence with the amino acids His Cys Ala Gly Arg in between the $\alpha 6$ helix and $\beta 5$ sheet positions on the protein. The sulfur thiol group of the Cys 160 is located for the nucleophilic attack on phosphate which makes a hydrogen-bonded ion pair with the buried side chains of amino acids Lys164 and Arg166. The phosphate group present in the protein is located at the $\mathrm{N}$-amino terminal of the $\alpha 6$ present within the helix axis. The dipole of $\alpha 6$ helix, Arg166 and the partial positive charges on the loop $\mathrm{P}$ amide hydrogens subscribes to the binding cleft which is complementary to the phosphate group. The carbonyl oxygen of the amino acid Cys160 is in direct contact with the amide nitrogen of the amino acid Glu32 containing side chains paired with the amino acids Arg56 and Arg64 (Grundner et al. 2005).

The amino acid Asp82 which is corresponding to Asp181 in the enzyme PTP1B is located inside the modified motif WPD with the sequence fixed partial denture (FPD). The motif FPD is located within the loop connecting $\alpha 4$ and $\beta 3$. The active center region consists of nearly all segments that are conserved in the sample of 60 PTPB homologs. The highest conserved regions include $\mathrm{P}$ loop, first turn of the following helix and the FPD loop which rings the binding site of the phosphate group. The $\alpha 3$ helix influences the depth, and the efficiency of the binding of the substrate to the cleft on the enzyme and sequences preceding the kink of the $\alpha 7$ helix are also conserved elements. The buried side-chain residues this preceding sequence of $\alpha 7$ is in contact with the P loop located within the active center influences the electrostatic potential at the catalytic center (Grundner et al. 2005).

\section{METHODS}

PTPs importance in tuberculosis infection, diabetes, and Cancer PTPs in tuberculosis

Mycobacterium tuberculosis is a Gram-positive and non-motile bacterium. Theia pathogenic bacterium contains various signal transduction pathways [1,2]. The Mycobacterium is the causative agent 


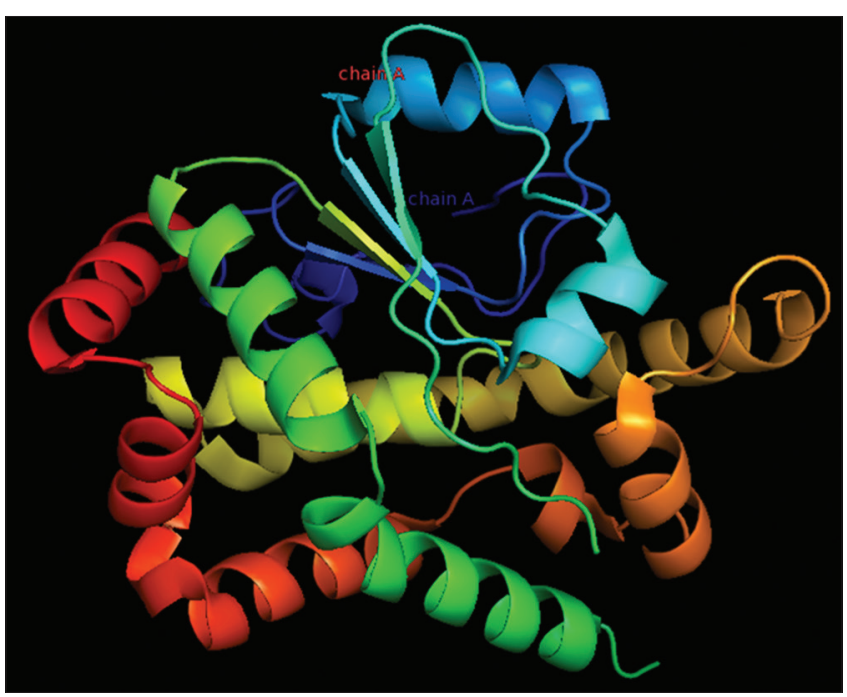

Fig. 1: Three-dimensional structure of mycobacterial enzyme protein tyrosine phosphatase $B$

for the deadly tuberculosis disease which affect one-third of world's total population because of its multidrug-resistant and extremely drug-resistant strains and as a result, of which there is an immediate necessity for alternative fast curative new and improved therapeutic regimen to augment the rate of treatment [1]. The main target for the mycobacteria is the host macrophages that play a major role in defense mechanism against foreign invading antigens such as a pathogen and destroy them [3]. The emerging treatment process aims to diagnose the target the virulence factors that are responsible for the development and replication of the causative microorganism $[4,5]$. There are two types of PTPs in Mycobacterium species genome: Mycobacterium PTPA (mPTPA) and mPTPB and lacks the PTK [5]. Both the mPTPA and $\mathrm{MPTPB}$ are released into the cytoplasm of the host macrophage. Although both mPTPA and $\mathrm{mPTPB}$ are responsible for TB infection, the major role is played by the MPTPB in TB infection in animals and humans. The two enzymes are needed for the optimal survival of the bacteria in the host macrophages as well as in animal models [6]. The mycobacteria lack endogenous PTP $\mathrm{mPTPA}$ and $\mathrm{mPTPB}$ reinforce the mycobacterial infections by acting on macrophage proteins to modulate the host-pathogen interactions. It has been revealed that the absence of tyrosine phosphorylation in the Mycobacterium, the mPTPA and MPTPB are likely to modify the host macrophage protein for the host-pathogen interactions. Fortunately, the genetic deletion of the MPTPB reduces the chances of survival and inhibits the survival of Mycobacterium in the interferon (IFN- $\gamma$ ) activated host macrophages, especially in the lungs of animals $[6,7]$. The inhibitions of both mPTPA and $\mathrm{mPTPB}$ activity increase the host intrinsic signaling pathways to eradicate the tuberculosis infection. The chemical inhibitors are more efficient than the biological inhibitors by reversing the modified host immune responses enhanced by the mycobacterial phosphatases and diminishing the mycobacterial survival in the host macrophages and are widely practiced [8]. Pharmacokinetic studies revealed that a chemical inhibitor isoniazid-rifampin-pyrazinamide (HRZ) is one of the effective inhibitor of tuberculosis in guinea pigs and other mammals [8].

\section{Role of $M P T P B$ in enhancing the survival of the Mycobacterium} in host macrophage

The mPTPB secreted by the Mycobacterium is considered one of the most vital virulence factors which are secreted into the cytoplasm of the host macrophage which is essential for the microbe to grow and infect. The IFN- $\gamma$ is the principal inflammatory cytokine which is the prime responsible factor the antimicrobial activity of the host macrophage against infectious pathogens. It is still now a hypothesis that mPTPB may promote the survival of the Mycobacterium in the host macrophage which targets the IFN- $\gamma$ mediated signal transduction pathways; however, the correct mechanism of this occurrence has not been clarified.

Tyrosine phosphatase as therapeutic targets for Type II diabetes Recent studies say that PTP is a negative regulator of the insulin regulatory signaling pathways (Kennedy 1999). The non-insulin relied on diabetes or Type II diabetes mellitus reaching plague proportions in many developing and developed countries. The prime reason for the Type II diabetes in humans is mainly caused as a result of obesity; around $75 \%$ of the obese people acquire diabetes (Kennedy 1999). There was been only very negligible studies on the activity of the enzyme PTP in Type II diabetes (Kennedy 1999). The quantification of the enzyme PTP activity form the muscle tissue of the obese, and insulin-resistant nondiabetic sufferers and controls of the lean insulin-sensitive patients were reported first by McGuire et al. They reported and concluded that in insulin-resistant sufferers, the PTP enzyme activity was around 33\% higher when compared to the controls and concluded by stating that this augmented levels of the enzyme PTP activity could be the reason for the Type II diabetes in sufferers. There were many more successive studies conducted to quantify the activity of the PTP enzyme in humans by Kusari et al. who quantified the activity of the enzyme from the lean controls, non-immune dependent diabetes mellitus and obese insulin-resistant non-diabetic sufferers stated concluded that there is a $21 \%$ decrease in the activity of the enzyme PTP activity in the muscle samples when compared to the lean controls, which is in contrast to the previous discovery of (McGuire et al.). The cause for this discrepancy between these two discoveries states that still, the role of PTP enzyme activity in humans remains unclear. On the other hand, PTP plays a major role in diabetes regimen in humans. PTP is a well-known target for obesity and Type II diabetes [9-11]. Recent studies reveal that PTP is also a potential target for breast Cancers. The PTP1B encoded by the PTPN1 gene is an expressed non-clinical receptor PTP containing 435 amino acids $[12,13]$. The amino acids contain the $\mathrm{N}$-amino terminal domain, hydrophobic C-carboxyl terminal, and two proline amino acidrich sequences. Biochemical studies reveal that PTP1B is a key negative regulator of leptin pathways and insulin, which are monitors and regulators of energy utilization, glucose equilibrium, and body weight balance [14]. PTP1B antibodies and inhibitors increase the insulin receptor substrates, insulin receptors, and STAT3 phosphorylation and stating that PTP1B inhibition could refine insulin sensitivity and leptin signal pathways $[15,16]$. The PTPN1 deficient in mice studies show the augmented insulin sensitivity and lectin sensitivity levels and exhibits lower insulin levels and lower blood glucose levels and also showed resistance to high-fat diet enhanced weight gain [17]. Diabetes mellitus a long-term metabolic disorder is caused mainly due to high blood sugar levels caused due to lack of secretion of insulin in the body by the pancreas. Type II diabetes is often due to the improper and poor nutritional diet and obesity and poor metabolism. The Type II diabetes is most common when compared to Type I diabetes in patients. With this regard, the PTP1B has been recognized as a unique novel drug target for diabetes and obesity [17]. One of the best drug target inhibitors is the second generation antisense inhibitor of PTP 1 or PTP1B is the ISIS113715 which showed improvements significantly enhances glucose metabolism along with the reduction in the low-density lipoprotein (LDL). They are also involved in the transfer of fat molecules around the body to every cell and improper regulation of LDL result in the progression of atherosclerosis due to the oxidation of LDL in the walls of arteries.

\section{Tyrosine phosphatase as therapeutic targets for Cancer cells}

PTP1B is considered as one of the best potential tumor suppressors; however, many recent advances reveal that PTP1B also act as tumor enhancer [18]. Recent studies have found that the PTP1B activates the breast cancer cells which are a non-receptor PTK family. PTP1B enzyme dephosphorylates the negative regulatory residue of Y530 in c-Src cancer cell lines. It has been recorded that the overexpression of the PTP1B genome in $72 \%$ of the 29 human breast cancer samples tested when compared healthy controls [19]. The overexpression of 
the PTP1B gene was observed and detected in all the stages of benign and malignant tumor cases, and its expression was correlated with the overexpression of theERBB2 genome which is a most commonly amplified receptor in PTK in breast cancer [20].

To further study about the role of PTP1B in breast cancer, several experiments were performed on mice. Mice expressing activated genes of ERBB2 were interrelated by crossing with the PTPN1-null mice [20]. The results were interpreted, and when compared to reference mice, the PTPN1-null mice showed a delay in the onset of a tumor and decreased rate of lung tumor metastasis. Deferred tumor outbreak and slow rate of metastasis were also observed after its treatment with PTP1B inhibitor. PTP1B also play a positive role in colorectal cancer cells (He et al. 2014). The inhibition of РТР1B leads the way for the discovery of novel strategy for the treatment of various human tumors [20].

\section{Selective PTP inhibitors}

\section{Inhibitors of Mycobacterium pathogenesis}

The Mycobacterium virulence in mammals can be inhibited by blocking the active center of the virulence causing enzyme, PTP. There are only a few commercial inhibitors available, namely L335-M34 and L01Z08 (Dutta et al., 2015); this is due to the presence of a highly conserved active site in the enzyme, bioavailability, and many difficulties in attaining the selectivity of inhibitors. The highly conserved regions of the enzyme PTPs provide many considerable challenges and threats that tend to selectively inhibit the target enzyme without disturbing the other phosphatase enzymes. To harbor phosphor-substrates, the PTP enzyme active site possesses positive charges which complement the negatively charged molecules in the high throughput screening campaigns which ultimately agonize from poor membrane permeability. To overcome the bioavailability issues, natural compounds, and plant phytochemicals which possess pharmacological drug PTP inhibitory properties and as well as FDA approved compounds can be utilized. For example, benzofuran salicylic acid is a well-known inhibitor of the PTP enzyme. The inhibitor L335-M34 (Fig. 2) is highly specific and selective against the enzyme mPTPA with inhibitory concentration $\left(\mathrm{IC}_{50}\right)$ of 160 nanomolar (nM) and does not have any significant role on PTPB or at a concentration of mPTPs $<3 \mu \mathrm{M}$ as MPTPA is a secreted virulence factor in the Mycobacterium that regulates the host antibacterial response [21]

The inhibitor L01Z08 (Fig. 3) of the L01 family consists of three highly selective inhibitors against mPTPB enzyme with $\mathrm{IC}_{50}$ of $2.5 \mu \mathrm{M}$ (Dutta et al., 2015). The inhibitor L01Z08 is the most potent available inhibitor for the mPTPB in the anti-tuberculosis activity [22].

The two inhibitors are the most effective commercial inhibitors used against the PTP activity thereby reducing the risk of tuberculosis in animals. Often, the two inhibitors L335-M34 and L01Z08 are used in combination which enhances the antitubercular regimen [21,22]. The two inhibitors in combination subsequently reduce the bacilli burden in the host macrophage (Dutta et al. 2015).

\section{Inhibitors of cancer}

The enzyme PTP1B of PTP enzyme class encoded by the PTPN1 gene is a non-receptor Class I PTP enzyme. This enzyme possesses a PTP domain, anchored hydrophobic endoplasmic reticulum present at the carboxyl-terminal. Recent researches revealed to activate c-Src by the dephosphorylation of inhibitory pTyr-530 [23]. This c-Src-mediated activation is required for the transformation of the MCF10A by the ErbB2 thereby contributing to the tumor development SW48 colon cancer in mammals $[24,25]$. P62Dok is a known substrate which p120RasGAP which shows negative regulatory functions on the Ras-Erk1/2 pathway [26]. Another feature of PTP1B is that this enzyme promotes cell migration [27]. The enzyme PTP1B is been overexpressed in several cancers/tumors such as ovarian and the breast cancers and correlates with the overexpression of ErbB2 [28]. Several studies on this enzyme reveal the mammary gland tumorigenesis in transgenic mouse models; the deficiency of the enzyme PTP1B delays the onset of tumors which are induced by ErbB2 and possesses resistance to metastasis of lungs; whereas the overexpression of PTP1B in mammary glands of humans results to the development of mammary gland metastasis $[20,29]$. Hence, the effect of PTP1B deficiency performed using a transgenic mouse as models correlate with the reduced activation of Erk signaling pathway [29]. Hence, these results conclude, the enzyme PTP1B is a tumor inducer and is a therapeutic potential drug target in ErbB2 receptor breast cancer. The PTP1B also performs dual roles in cancer that is both the tumor promoter and tumor suppressor [29]. An experiment on PTP1B deficient p53 null mice is more susceptible to the B-cell lymphomas correlating with the reduced natural cell death (apoptosis) and is a negative regulator. As soon as the identification of PTP1B drug targets for cancers, several inhibitors have been discovered to inhibit its activity [30].

The compound with $\mathrm{IC}_{50} 120 \mathrm{nM}$ (Fig. 4) (Han et al., 2008) acts as a potential orally bioavailable inhibitor with a very good pharmacological and pharmacokinetic property [31-33]. This compound also works efficiently against controlling blood sugar levels as well. This compound works well when administered to ErbB2 induced mammary gland tumor null mice model organism through oral administration with a dosage of $30 \mathrm{mg} / 21$ consecutive days delays the mammary gland tumor development $[30,31]$. And also this compound was not specific to the PTP1B enzyme, and possess cross-inhibition of many other PTPs contributes to the anti-tumor effects. Hence, this research evidence

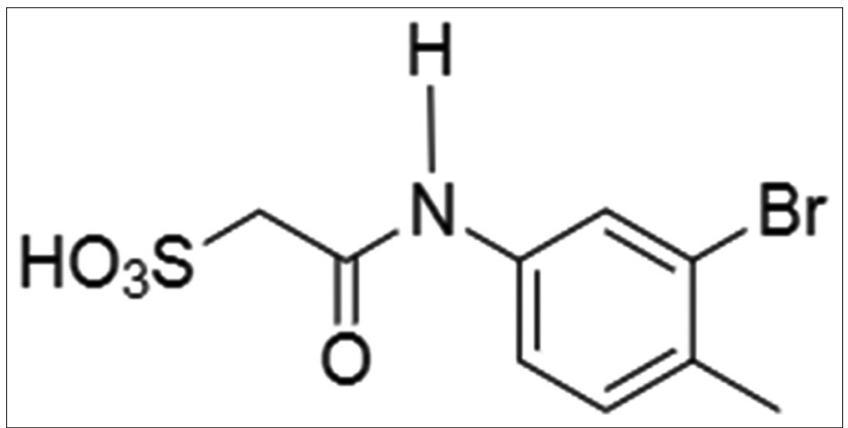

Fig. 2: Structure of the L335-M34 inhibitor

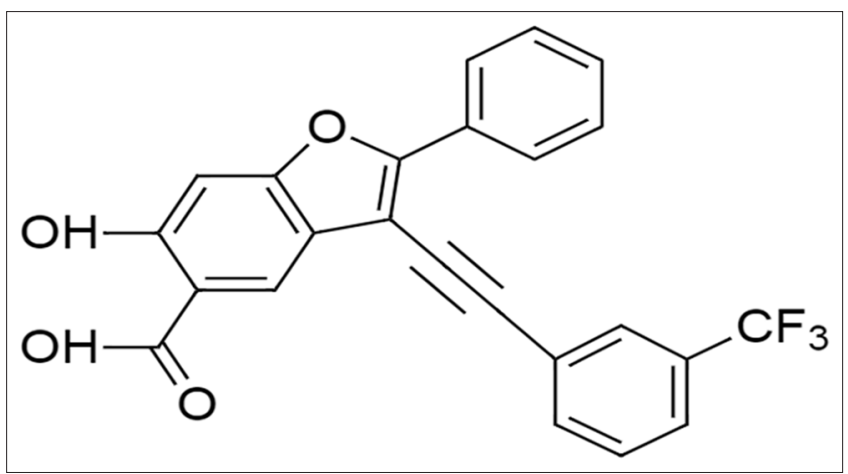

Fig. 3: Structure of the L01Z08 inhibitor

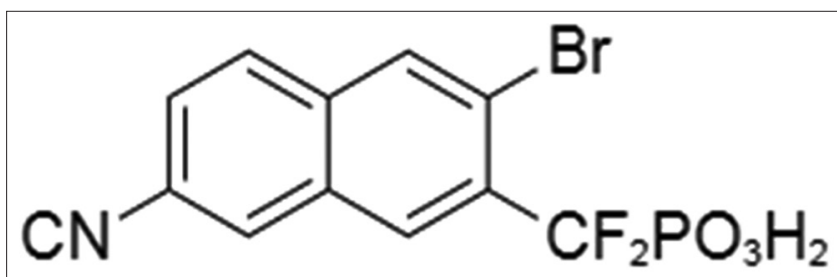

Fig. 4: Structure of the compound inhibiting protein tyrosine phosphatase 1B 
contributes the truth of using PTP1B as drug targets for the intercession of ErbB2 dependent breast cancers [32,33].

\section{Inhibitors of diabetes mellitus}

After the discovery of PTP1B as molecular drug targets, there are several pharmaceutical companies involved in the discovery to inhibit the activity of the enzyme, since targeting the active site of the PTP1B enzyme will be more effective in the regimen of disease like diabetes thereby increase the insulin sensitivity in mammals [33]. The enzyme PTP1B dephosphorylates the insulin-producing receptors in the organism that is responsible for insulin signaling and secretion and thereby its contribution to its resistance to Type II diabetes in mammals [33]. However, misfortunately, it is difficult to determine a safe, selective, more efficient, and effective inhibitors of the PTP1B enzyme and is probably critical to design the inhibitor [34]. One major challenge in the development of inhibitors for Type II diabetes is due to cell permeability to reach the target. Several structure-based drug designing processes of molecular ligand-macromolecule docking are been widely performed to inhibit this enzyme [34]. Several researchers came up with the idea of using vanadium compounds as inhibitors. However, the vanadium compounds are competitive inhibitors of the enzyme PTP1B and are not considered specific to the target [35]. The Ki values (inhibition coefficient) of vanadium inhibitors are 380 nM. Vanadium is not well absorbed in the body; however, organic vanadium compounds have a lower Ki value and are well absorbed in the body $[36,37]$.

Clinical trials were performed on vanadium compounds like vanadyl sulfate showed a better efficacy, and heavier dosage was less practiced due to augmented side effects on gastro intestine. Groves et al. performed several experiments and discovered that the attachment of difluoromethylene phosphonic acid group to one of the peptide substrate of PTP1B has shown to possess an effective quality of an inhibitor. Bisphophorylated substrate tends to bind more efficiently with the binding sites of the PTP1B enzyme having a very low nM concentration of inhibition coefficient. Salmeen et al. showed that the PTP1B uses its second phosphate binding site through crystallographic studies of the enzyme protein, and moreover, inhibitory peptides did not bind to the second phosphate binding site, instead second phosphate group of the enzyme PTP1B has interacted with the amino acid Arg $47[10,38]$. Thus, these studies reveal that the other interactions connecting PTP1B and the insulin receptors may tend to place the second pTyr into the second phosphate binding region of the enzyme [38]. There are several other known classes of novel inhibitor compounds such as arylbenzonaphthofurans and arylbenzonaphthothiophenes that have proven to augmented insulin sensitivity in model organisms in rodents [11,39]

Ertiprotafib (Fig. 5) a lipophilic molecule (Shlomit Koren 2007), after efforts were studied and are currently used for the treatment of Type II diabetes by increasing the insulin sensitivity. This compound has successfully reached levels up to Phase II clinical trials in the regimen of Type II diabetes and showed very good effects. In vivo treatments of ertiprotafib on rodents showed to be inconsistent in PTP1B inhibition and are shown to be an effective inhibitor of PTP1B and also an activator of PPAR $\gamma$ and $\alpha$ subunits $[11,31,40]$.

\section{Strategies that modulate PTP activity}

There are many ways that modulate the activity of the PTP enzyme; one such design is that to develop mimetic dependent non-hydrolysable small molecules. This method is one of the most popularly used and has successfully produced various potential inhibitors of PTP $[17,41]$. However, this strategy has several challenges due to the specificity of conserved PTP structure and also due to cell permeability due to positively charged active sites of PTP and also several in vitro and in vivo studies have to be performed to determine the identification optimization specific substrates for inhibition on the target, analyzing the toxicity and pharmacological drug-like properties profiling which requires great efforts. The cell permeability and inhibitors specificity

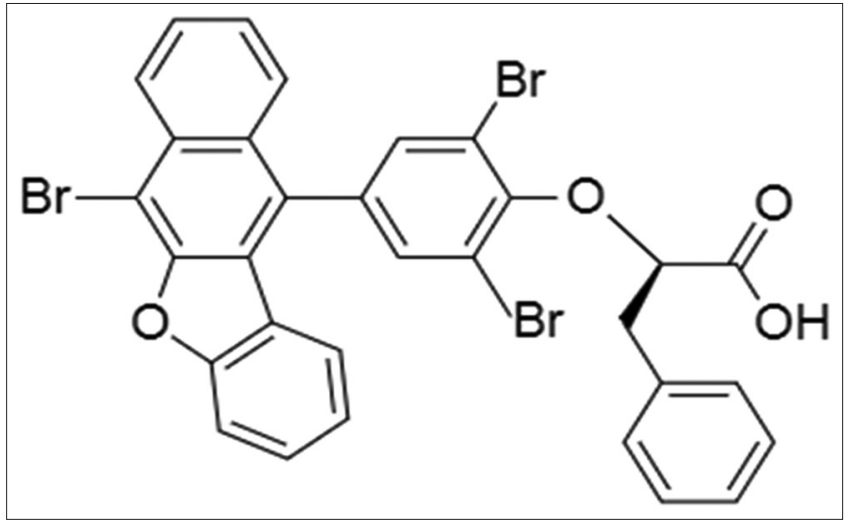

Fig. 5: Structure of ertiprotafib

are the major factors that are to be considered for creating new drug targets to inhibit the PTP activity as these enzyme domains are tumor suppressors and should not be unintentionally targeted [21].

Targeting the allosteric sites of PTP1B creates high cell permeability and high specificity inhibitors and allosteric sites are not needed to possess negative charges and as a result of which making the pharmacological properties more efficient and potent [42]. This also has challenges as the allosteric sites are not well defined as the active sites of the enzyme. Other strategies include mechanism-dependent inhibitor techniques that inactivate the PTP enzyme's catalytic cysteine amino acid residues by oxidation or by any other modifications in its terminals. This type of strategy takes place in quinone based inhibitors. The quinone based inhibitor induces reactive oxygen species and may cause in vivo toxicity by inactivating the redox-sensitive enzymes [43]. The in vitro activities are not suitable and not pleading for drug development $[43,44]$. The irreversible and selective kinase inhibitors have generated covalent enzyme inhibitors [44-46]. In comparison with quinone based PTP inhibitors, the irreversible inhibitors do not target all the redox-sensitive enzymes in the cell; instead, the inhibitors target only one sensitive enzyme [46]. Recent studies reveal that PTP1B and low molecular weight PTP have reported to decrease the blood glucose levels, increase the insulin regulation, and control obesity in clinical studies as a result, of which makes it is more liable for therapeutic applications $[47,48]$. In many conditions, small interfering RNAs can also be used in targeting PTP through similar mechanism pathways $[49,50]$.

\section{CONCLUSION}

The PTP enzymes dysregulation is the cause for major diseases including tuberculosis, cancer, diabetes, and obesity in humans [2,51-54]. These diseases can be prevented by inhibiting the activity of the PTP enzyme and play a major role in drug discovery and development [51,55]. PTP acts as potential drug targets which enable strategies to develop modern treatment regimen [56-59]. For instance, the PTP1B and the low molecular weight PTP are well known for their activity against tumor and insulin resistance thereby suppressing the tumor/cancer $[55,60]$. SHP2, PRLs, and LMWPTP phosphatases are involved in controlling tumorigenesis, which led the way for the development of various drugs against metastasis tumor in humans [61]. Although a large number of PTP targets are recognized, there is a lack in the commercialization of PTP inhibitors by pharmaceutical industries; this is because of several key challenges that block the strategy for the development of PTP drug targets. Due to highly conserved active sites and diverged folds, it becomes difficult to target only PTP targets and PTP contains highly positive charges in their active site and contains cysteine amino acid residues which are catalytic [56,57]. Several natural compounds such as plant phytochemicals such as flavonoids, terpenoids, and phenolic have found to be effective inhibitors of the PTP enzyme by binding to the active center thereby inhibiting the activity of the enzyme and other secondary metabolites [62,63]. Recent discoveries on plant 
phytochemicals against the PTP enzymes include Psidium guajava (Myrtaceae) leaf extracts which have one of the highest efficiency on the PTP enzyme active center inhibition to cure diabetes [63,64]. Natural plant phytochemicals such as curcumin as a ligand also showed high efficiency in binding with the active site of the PTP enzyme in prostate cancers through in silico docking analysis $[65,66]$. Compounds isolated from Sorbus commixta (Japanese flowering plant); lupeol and lupenone are also found to inhibit the PTP1B enzyme efficiently [67]. Therefore, PTP is an enzyme and is used as a novel drug target in the regimen of several mammalian diseases and disorders.

\section{ACKNOWLEDGMENT}

We, the authors sincerely thank Vels Institute of Science, Technology and Advanced Studies management for their kind support and facilities provided to carry out our review work.

\section{CONFLICTS OF INTEREST}

The authors declare that they do not have any conflicts of interest.

\section{REFERENCES}

1. Dutta NK, He R, Pinn ML, He Y, Burrows F, Zhang ZY, et al. Mycobacterial protein tyrosine phosphatases A and B inhibitors augment the bactericidal activity of the standard anti-tuberculosis regimen. ACS Infect Dis 2016;2:231-9.

2. Cohen P, Alessi DR. Kinase drug discovery-what's next in the field? ACS Chem Biol 2012;8:96-104.

3. Kempker RR, Kipiani M, Mirtskhulava V, Tukvadze N, Magee MJ, Blumberg HM, et al. Acquired drug resistance in Mycobacterium tuberculosis and poor outcomes among patients with multidrugresistant tuberculosis. Emerg Infect Dis 2015;21:992-1001.

4. Clatworthy AE, Pierson E, Hung DT. Targeting virulence: A new paradigm for antimicrobial therapy. Nat Chem Biol 2007;3:541-8.

5. Silva AP, Tabernero L. New strategies in fighting TB: Targeting Mycobacterium tuberculosis-secreted phosphatases MptpA \& MptpB. Future Med Chem 2010;2:1325-37.

6. Singh R, Rao V, Shakila H, Gupta R, Khera A, Dhar N, et al. Disruption of mptpB impairs the ability of Mycobacterium tuberculosis to survive in guinea pigs. Mol Microbiol 2003;50:751-62.

7. Wong D, Bach H, Sun J, Hmama Z, Av-Gay Y. Mycobacterium tuberculosis protein tyrosine phosphatase (PtpA) excludes host vacuolar-H+-ATPase to inhibit phagosome acidification. Proc Natl Acad Sci U S A 2011;108:19371-6.

8. Zeng LF, Xu J, He Y, He R, Wu L, Gunawan AM, et al. A facile hydroxyindole carboxylic acid based focused library approach for potent and selective inhibitors of mycobacterium protein tyrosine phosphatase B. ChemMedChem 2013;8:904-8.

9. He RJ, Yu ZH, Zhang RY, Zhang ZY. Protein tyrosine phosphatases as potential therapeutic targets. Acta Pharmacol Sin 2014;35:1227-46.

10. Yao ZJ, Ye B, Wu XW, Wang S, Wu L, Zhang ZY, et al. Structure-based design and synthesis of small molecule protein-tyrosine phosphatase 1B inhibitors1. Bioorg Med Chem 1998;6:1799-810.

11. Tobin JF, Tam S. Recent advances in the development of small molecule inhibitors of PTP1B for the treatment of insulin resistance and Type 2 diabetes. Curr Opin Drug Discov Devel 2002;5:500-12.

12. Tonks NK, Diltz CD, Fischer EH. Purification of the major proteintyrosine-phosphatases of human placenta. J Biol Chem 1988;263:6722-30.

13. Tonks NK, Diltz CD, Fischer EH. Characterization of the major proteintyrosine-phosphatases of human placenta. J Biol Chem 1988;263:6731-7.

14. Zhang ZY, Lee SY. PTP1B inhibitors as potential therapeutics in the treatment of Type 2 diabetes and obesity. Expert Opin Investig Drugs 2003; 12:223-33

15. Kaszubska W, Falls HD, Schaefer VG, Haasch D, Frost L, Hessler $\mathrm{P}$, et al. Protein tyrosine phosphatase 1B negatively regulates leptin signaling in a hypothalamic cell line. Mol Cell Endocrinol 2002;195:109-18.

16. Lund IK, Hansen JA, Andersen HS, Møller NP, Billestrup N. Mechanism of protein tyrosine phosphatase 1B-mediated inhibition of leptin signalling. J Mol Endocrinol 2005;34:339-51.

17. Combs AP. Recent advances in the discovery of competitive protein tyrosine phosphatase 1B inhibitors for the treatment of diabetes, obesity, and cancer. J Med Chem 2009;53:2333-44.

18. Lessard L, Stuible M, Tremblay ML. The two faces of PTP1B in cancer. Biochim Biophys Acta 2010;1804:613-9.
19. Wiener JR, Kerns BJ, Harvey EL, Conaway MR, Lglehart JD, Berchuck A, et al. Overexpression of the protien tyrosine phosphatase PTP1B in human breast cancer: Association with p185c-erbB-2 protein expression. J Natl Cancer Inst 1994;86:372-8.

20. Bentires-Alj M, Neel BG. Protein-tyrosine phosphatase $1 \mathrm{~B}$ is required for HER2/Neu-induced breast cancer. Cancer Res 2007;67:2420-4.

21. He Y, Zeng LF, Yu ZH, He R, Liu S, Zhang ZY, et al. Bicyclic benzofuran and indole-based salicylic acids as protein tyrosine phosphatase inhibitors. Bioorg Med Chem 2012;20:1940-6.

22. Moreira W, Ngan GJ, Low JL, Poulsen A, Chia BC, Ang MJ, et al. Target mechanism-based whole-cell screening identifies bortezomib as an inhibitor of caseinolytic protease in mycobacteria. MBio 2015;6:e0253-15.

23. Bjorge JD, Pang A, Fujita DJ. Identification of protein-tyrosine phosphatase 1B as the major tyrosine phosphatase activity capable of dephosphorylating and activating c-src in several human breast cancer cell lines. J Biol Chem 2000;275:41439-46.

24. Arias-Romero LE, Saha S, Villamar-Cruz O, Yip SC, Ethier SP, Zhang ZY, et al. Activation of src by protein tyrosine phosphatase 1B is required for erbB2 transformation of human breast epithelial cells. Cancer Res 2009;69:4582-8.

25. Zhu S, Bjorge JD, Fujita DJ. PTP1B contributes to the oncogenic properties of colon cancer cells through src activation. Cancer Res 2007;67:10129-37

26. Dubé N, Cheng A, Tremblay ML. The role of protein tyrosine phosphatase 1B in ras signaling. Proc Natl Acad Sci U S A 2004;101:1834-9.

27. Zhang Z, Lin SY, Neel BG, Haimovich B. Phosphorylated $\alpha$-actinin and protein-tyrosine phosphatase $1 \mathrm{~B}$ coregulate the disassembly of the focal adhesion kinase-Src complex and promote cell migration. J Biol Chem 2006;281:1746-54

28. Wiener JR, Hurteau JA, Kerns BJ, Whitaker RS, Conaway MR, Berchuck A, et al. Overexpression of the tyrosine phosphatase PTP1B is associated with human ovarian carcinomas. Am J Obstet Gynecol 1994; 170:1177-83

29. Julien SG, Dubé N, Read M, Penney J, Paquet M, Han Y, et al. Protein tyrosine phosphatase 1B deficiency or inhibition delays erbB2-induced mammary tumorigenesis and protects from lung metastasis. Nat Genet 2007;39:338-46.

30. Han Y, Belley M, Bayly CI, Colucci J, Dufresne C, Giroux A, et al. Discovery of [(3-bromo-7-cyano-2-naphthyl)(difluoro) methyl] phosphonic acid, a potent and orally active small molecule PTP1B inhibitor. Bioorg Med Chem Lett 2008;18:3200-5.

31. Erbe DV, Wang S, Zhang YL, Harding K, Kung L, Tam M, et al. Ertiprotafib improves glycemic control and lowers lipids via multiple mechanisms. Mol Pharmacol 2005;67:69-77.

32. Lantz KA, Hart SG, Planey SL, Roitman MF, Ruiz-White IA, Wolfe HR, et al. Inhibition of PTP1B by trodusquemine (MSI-1436) causes fat-specific weight loss in diet-induced obese mice. Obesity 2010;18:1516-23.

33. Scott LM, Lawrence HR, Sebti SM, Lawrence NJ, Wu J. Targeting protein tyrosine phosphatases for anticancer drug discovery. Curr Pharm Des 2010;16:1843-62.

34. Bibi SH, Kalsoom SA, Rashid HA. Ligand based approach for pharmacophore generation for identification of novel compounds having antidiabetic activity. Int J Pharm Pharm Sci 2013;5:303-14.

35. Fantus IG, Kadota S, Deragon G, Foster B, Posner BI. Pervanadate [peroxide(s) of vanadate] mimics insulin action in rat adipocytes via activation of the insulin receptor tyrosine kinase. Biochemistry 1989;28:8864-71.

36. Posner BI, Faure R, Burgess JW, Bevan AP, Lachance D, ZhangSun $\mathrm{G}$, et al. Peroxovanadium compounds. A new class of potent phosphotyrosine phosphatase inhibitors which are insulin mimetics. J Biol Chem 1994;269:4596-604.

37. Cohen N, Halberstam M, Shlimovich P, Chang CJ, Shamoon H, Rossetti $\mathrm{L}$, et al. Oral vanadyl sulfate improves hepatic and peripheral insulin sensitivity in patients with non-insulin-dependent diabetes mellitus. J Clin Invest 1995;95:2501-9.

38. Sarmiento M, Puius YA, Vetter SW, Keng YF, Wu L, Zhao Y, et al. Structural basis of plasticity in protein tyrosine phosphatase 1B substrate recognition. Biochemistry 2000;39:8171-9.

39. Wrobel J, Sredy J, Moxham C, Dietrich A, Li Z, Sawicki DR, et al. PTP1B inhibition and antihyperglycemic activity in the ob/ob mouse model of novel 11-arylbenzo[b]naphtho[2,3-d]furans and 11-arylbenzo[b] naphtho[2,3-d]thiophenes. J Med Chem 1999;42:3199-202.

40. Peterson RL, Casciotti L, Block L, Goad ME, Tong Z, Meehan JT, et al. Mechanistic toxicogenomic analysis of WAY-144122 administration in 
sprague-dawley rats. Toxicol Appl Pharmacol 2004;196:80-94.

41. Bialy L, Waldmann H. Inhibitors of protein tyrosine phosphatases: Next-generation drugs? Angew Chem Int Ed 2005;44:3814-39.

42. Wiesmann C, Barr KJ, Kung J, Zhu J, Erlanson DA, Shen W, et al. Allosteric inhibition of protein tyrosine phosphatase 1B. Nat Struct Mol Biol 2004;11:730-7.

43. Bolton JL, Trush MA, Penning TM, Dryhurst G, Monks TJ. Role of quinones in toxicology. Chem Res Toxicol 2000;13:135-60.

44. Monks TJ, Jones DC. The metabolism and toxicity of quinones, quinonimines, quinone methides, and quinone-thioethers. Curr Drug Metab 2002;3:425-38.

45. Barf T, Kaptein A. Irreversible protein kinase inhibitors: Balancing the benefits and risks. J Med Chem 2012;55:6243-62.

46. Sanderson K. Irreversible kinase inhibitors gain traction. Nat Rev Drug Discov 2013;12:649-51

47. Pandey SK, Yu XX, Watts LM, Michael MD, Sloop KW, Rivard AR, et al. Reduction of low molecular weight protein-tyrosine phosphatase expression improves hyperglycemia and insulin sensitivity in obese mice. J Biol Chem 2007;282:14291-9.

48. Rondinone CM, Trevillyan JM, Clampit J, Gum RJ, Berg C, Kroeger P, et al. Protein tyrosine phosphatase $1 \mathrm{~B}$ reduction regulates adiposity and expression of genes involved in lipogenesis. Diabetes 2002;51:2405-11.

49. Zinker BA, Rondinone CM, Trevillyan JM, Gum RJ, Clampit JE, Waring JF, et al. PTP1B antisense oligonucleotide lowers PTP1B protein, normalizes blood glucose, and improves insulin sensitivity in diabetic mice. Proc Natl Acad Sci U S A 2002;99:11357-62.

50. Barr AJ. Protein tyrosine phosphatases as drug targets: Strategies and challenges of inhibitor development. Future Med Chem 2010;2:1563-76.

51. He R, Zeng LF, He Y, Zhang S, Zhang ZY. Small molecule tools for functional interrogation of protein tyrosine phosphatases. FEBS J 2013;280:731-50.

52. Kennedy BP. Role of protein tyrosine phosphatase-1B in diabetes and obesity. Biomed Pharmacother 1999;53:466-70.

53. McGuire MC, Fields RM, Nyomba BL, Raz I, Bogardus C, Tonks NK, et al. Abnormal regulation of protein tyrosine phosphatase activities in skeletal muscle of insulin-resistant humans. Diabetes 1991;40:939-42.

54. Worm D, Vinten J, Staehr P, Henriksen JE, Handberg A, BeckNielsen $\mathrm{H}$, et al. Altered basal and insulin-stimulated phosphotyrosine phosphatase (PTPase) activity in skeletal muscle from NIDDM patients compared with control subjects. Diabetologia 1996;39:1208-14.
55. Møller NP, Iversen LF, Andersen HS, McCormack JG. Protein tyrosine phosphatases (PTPs) as drug targets: Inhibitors of PTP-1B for the treatment of diabetes. Curr Opin Drug Discov Devel 2000;3:527-40.

56. Grundner $\mathrm{C}, \mathrm{Ng} \mathrm{HL}$, Alber T. Mycobacterium tuberculosis protein tyrosine phosphatase ptpB structure reveals a diverged fold and a buried active site. Structure 2005; 13:1625-34

57. Kolmodin K, Aqvist J. The catalytic mechanism of protein tyrosine phosphatases revisited. FEBS Lett 2001;498:208-13.

58. Zhang ZY. Protein tyrosine phosphatases: Prospects for therapeutics. Curr Opin Chem Biol 2001;5:416-23.

59. Hooft van Huijsduijnen R, Bombrun A, Swinnen D. Selecting protein tyrosine phosphatases as drug targets. Drug Discov Today 2002;7:1013-9.

60. Murillo AC, Li HY, Alber T, Baker EN, Berger JM, Cherney LT, et al. High throughput crystallography of TB drug targets. Infect Disord Drug Targets 2007;7:127-39.

61. Alonso A, Sasin J, Bottini N, Friedberg I, Friedberg I, Osterman A, et al. Protein tyrosine phosphatases in the human genome. Cell 2004;117:699-711.

62. Jiang CS, Liang LF, Guo YW. Natural products possessing protein tyrosine phosphatase $1 \mathrm{~B}$ (PTP1B) inhibitory activity found in the last decades. Acta Pharmacol Sin 2012;33:1217-45.

63. Thareja S, Aggarwal S, Bhardwaj TR, Kumar M. Protein tyrosine phosphatase 1B inhibitors: A molecular level legitimate approach for the management of diabetes mellitus. Med Res Rev 2012;32:459-517.

64. Oh WK, Lee CH, Lee MS, Bae EY, Sohn CB, Oh H, et al. Antidiabetic effects of extracts from Psidium guajava. J Ethnopharmacol 2005;96:411-5.

65. Inbathamizh L, Padmini E. Moringa oleifera flower compounds as potent ligands to drug targets in PC3 cell lines-an in silico analysis. Int J Pharm Pharm Sci 2013;5:377-83.

66. Singh AN, Baruah MM, Sharma N. Structure based docking studies towards exploring the potential anti-androgen activity of selected phytochemicals against prostate cancer. Sci Rep 2017;7:1955.

67. Na M, Kim BY, Osada H, Ahn JS. Inhibition of protein tyrosine phosphatase 1B by lupeol and lupenone isolated from Sorbus commixta. J Enzyme Inhib Med Chem 2009;24:1056-9.

67. Salmeen A, Andersen JN, Myers MP, Tonks NK, Barford D. Molecular basis for the dephosphorylation of the activation segment of the insulin receptor by protein tyrosine phosphatase 1B. Mol cell 2000 Dec $1 ; 6(6): 1401-12$. 